\title{
Phylogenetic Analysis of Human Papillomavirus 16 and 52 L1 Gene from Cervical Cancer in Bandung, Indonesia
}

\author{
Mutia Latief ${ }^{1, *}$, Ika Agus Rini ${ }^{2}$, Gita Widya Pradini ${ }^{3}$, Gatot Nyarumenteng Adhipurnawan Winarno ${ }^{4}$, \\ Edhyana Sahiratmadja ${ }^{5}$, Herman Susanto ${ }^{4}$ \\ ${ }^{1}$ Faculty of Medicine, Padjadjaran University, Jl. Jatinangor-Sumedang Km 21 Jatinangor, Sumedang, Indonesia \\ ${ }^{2}$ Center for The Study of Oncology, Faculty of Medicine, Padjadjaran University, Jl. Eickman No. 38, Bandung, Indonesia \\ ${ }^{3}$ Department Microbiology and Parasitology, Faculty of Medicine, Universitas Padjadjaran, Jl. Eickman No. 38, Bandung, Indonesia \\ ${ }^{4}$ Department of Obstetrics and Ginecology, Hasan Sadikin Hospital/ Faculty of Medicine, Padjadjaran University, Jl. Eickman No. 38, Bandung, Indonesia \\ ${ }^{5}$ Department of Biochemistry, Faculty of Medicine, Padjadjaran University, Jl. Jatinangor-Sumedang Km 21 Jatinangor, Sumedang, Indonesia \\ *Corresponding author. E-mail: herman.susanto@unpad.ac.id
}

Received date: Jan 1, 2017; Revised date: July 7, 2017; Accepted date: July 24, 2017

\section{Abstract}

$\mathrm{B}$ ACKGROUND: Chronic infection with high-risk type of human papillomavirus (HPV) can cause cervical cancer. Previous studies showed that multiple infections of HPV are found in cervical cancer caused by multiple HPV infections and the most common are HPV-16 and HPV-52. The origin of HPV-16 circulating in Indonesia varies. Purpose of this study was to explore the origin of multiple infections of HPV-52 and HPV-16 in cervical cancer by using a phylogenetic tree.

METHODS: During July-November 2010, 100 women were diagnosed with cervical cancer in the Department of Obstetrics and Gynecology, Dr. Hasan Sadikin General Hospital, Bandung, Indonesia. Only 96 patients were involved in this study. Ninety-six samples of HPV deoxyribonucleic acid (DNA) were isolated from biopsied tissue of cervical cancer. Multiple infections of HPV genotypes HPV-16 and HPV-52 were confirmed by using the linear assay for HPV genotyping test. Afterward, HPV$52 \mathrm{~L} 1$ gene was amplified by using self-designed primer. L1 gene was also sequenced and analyzed using phylogenetic program (MEGA6.06).

RESULTS: The result of phylogenetic tree construction showed that isolated HPV-52 originated from multiple infections of HPV-16 and HPV-52 from cervical cancer patients in Bandung were in a subgroup with isolates originating from EU077219 Canada (America) and KT799980 southwest China (Asia). Isolate HPV-16 in one subgroup with isolates originating from KU951191.1 (Southwest China).

CONCLUSION: L1 gene sequence from multiple infections isolated from HPV-16 and HPV-52 from cervical cancer patients in Bandung refers to the variation of $\mathrm{L} 1$ gene reported from Canada and southwest China. This proves that Indonesia's HPV clusters are located in the strains found in America and Asia.

KEYWORDS: multiple infections, HPV-16, HPV-52, L1 gene, phylogenetic

Indones Biomed J. 2018; 10(1): 40-5

\section{Introduction}

Cervical cancer is the second rank of caused-death cancer after breast cancer in woman. Based on the data from World Cancer Statistics, incidence of cervical cancer case is estimated at 528,000 and 266,000 death cases worldwide.(1) An estimated $80 \%$ of cervical cancer death occurs in developing countries.(2) High prevalence of cervical cancer in Indonesia is as many as $11.4 \%$.(3) Totally 20,928 Indonesian women are diagnosed with cervical cancer and 9,498 death caused by cervical cancer.(4)

The primary cause of cervical cancer is the human papillomavirus (HPV) infection.(1,3) HPV is non-enveloped 
deoxyribonucleic acid (DNA) virus that affects skin or mucosa cells.(5) International consensus divides HPV into two groups based on L1 gene sequence. The first group is the high-risk genotype, which includes genotypes 16,18 , $31,33,35,39,45,51,52,56,58,59$ and 66 that play a role in etiology of cervical cancer.(5) While the other group is the low-risk genotypes including genotypes 6, 11, 42, 43 and 44 cause genital warts.(5,6) HPV DNA genomic have a double and circular chain of 7,200-8,000 base pairs. HPV genomes are divided into three sections. The first region is long control region (LCR) which regulates the expression and replication; the second region is early protein open reading frame (ORF) consisting of E1, E2, E4, E5, E6 and E7 that are oncogenic; and the third region is late protein encodes which is a protein that plays a role in L1 and L2 in the formation of the viral capsid.(7) HPV isolates can be classified based on the sequences of the L1 genes. According to the Nomenclature Committee on Papillomavirus HPV genomic is said to have a molecular variant if there is a similarity of more than $98 \%$ of the prototype L1 gene and have different types if the genetic variation is more than $10 \%$. HPV with a genetic variation of $2-10 \%$ is called subtype, while the genetic variation with less than $2 \%$ variation is called intratype. The L1 gene variations can be analyzed by using phylogenetic tree to determine the origin.(8)

Based on the previous research in Indonesia, cervical cancer is most often caused by infection of HPV-16 HPV-18 and HPV-52.(9) HPV-52 was found as the cause of cervical cancer with the highest prevalence in general population with normal cervical examination. Besides HPV-52, infection is often found in multiple infections either with HPV-16 or HPV-18.(10) The purpose of this research was to study the genetic variation of L1 gene by tracing the origin of HPV-16 and HPV-52 infections of cervical cancer isolates in Bandung by creating a phylogenetic tree. By knowing the origin, it is expected to provide information on the use of vaccines given as a preventive measure for cervical cancer in Indonesia.

\section{Methods}

\section{Research Design}

This was a descriptive study. During July-November 2010 as many as 100 women were diagnosed with cervical cancer in the Department of Obstetrics and Gynecology, Dr. Hasan Sadikin General Hospital, Bandung. Only 96 patients were involved in this study. The inclusion of cervical cancer tissue biopsies was performed from patients who subsequently had confirmed histopathological diagnoses based on the classification of the World Health Organization (WHO). General information includes patient's age, histopathologic diagnoses and date of diagnoses were collected from patient's medical records. Out of the 96 patients, there were obtained only 54 samples from patients who had consented for genotyping examination. Permission to conduct this study was given by the Health Research Ethics Committee of the Faculty of Medicine, Padjadjaran University, Bandung No. 874/UN6. C1.3.2/KEPK/PN/2016.

\section{Amplification of HPV-16 and HPV-52 L1 Gene}

HPV-16 and HPV-52 were amplified by PCR using primers based on sequence provided by Genebank of www.ncbi.nlm. nih.gov to obtain fragments of L1 gene HPV-16 and HPV-52 (Table 1). The process of PCR for HPV-16 L1 was performed at the denaturation temperature of $95^{\circ} \mathrm{C}$ for 30 seconds, the temperature amplification $51.1^{\circ} \mathrm{C}$ for 30 seconds $(40$ cycles), and extension temperature $72^{\circ} \mathrm{C}$ for 1 minute 30 seconds and $72^{\circ} \mathrm{C}$ for 5 minutes. While the process of PCR for HPV-52 L1 was carried out at a temperature of $95^{\circ} \mathrm{C}$ for 3 minutes, cycles of denaturation at a temperature of $95^{\circ} \mathrm{C}$ for 30 seconds, the temperature amplification $48^{\circ} \mathrm{C}$ for 30 seconds ( 35 cycles), and the temperature extension $72^{\circ} \mathrm{C}$ for 1 minute 30 second and $72^{\circ} \mathrm{C}$ for 5 minutes. PCR results were obtained from imaging process of electrophoresis on agarose gel $1 \%$ with a voltage of 100 volt $400 \mathrm{~mA}$ current for 30 minutes. PCR results then were processed through

Table 1. Primary L1 HPV-16 and HPV-52.

\begin{tabular}{ccccc}
\hline L1 HPV & Annealing & $\begin{array}{c}\text { Length of } \\
\text { PCR Product }\end{array}$ & \multicolumn{1}{c}{ Primer } \\
\hline L1 HPV-52 & $48^{\circ} \mathrm{C}$ & $1500 \mathrm{bp}$ & Forward & 5'-TGG TAC AGA TTT TAT TTT ACA TCC-3' \\
& & Reverse & 5'-TTA CCT TTT AAC CTT TTT CTT CT-3' \\
L1 HPV-16 & $51.1^{\circ} \mathrm{C}$ & $1500 \mathrm{bp}$ & Forward & 5'-CAA TTA TTG CTG ATG CAG GTG ACT-3' \\
& & & Reverse & 5'-CTT ACA GCT TAC GTT TTT TGC G-3' \\
\hline
\end{tabular}


sequencing performed at 1st BASE DNA sequencing (Kuala Lumpur, Malaysia) to obtain the sequence of the gene sequence of nitrogenous bases L1 HPV-16 and HPV-52.

\section{Data Analysis}

The data were analyzed using sequences Bioedit software (version 7.2.5.0), nucleotide BLAST, and ClustalX 2.1. Making the phylogenetic tree was done by using software MEGA 6.06 (11) and the HPV-16 and HPV-52 relationship was analyzed by comparing sequences of the base sequence of nitrogen from L1 gene HPV-16 and HPV-52 isolates of patients with cervical cancer in Bandung with those in other countries.

\section{Results}

The sample used in this study came from patients who had been diagnosed with cervical cancer in the Department of Obstetrics and Gynecology, Dr. Hasan Sadikin General Hospital Bandung with degree IIA/IIB FIGO classification based on the histopathology type of Squamous Cell Carcinoma (SCC).(10) The cervical cancer tissue biopsy then underwent DNA isolation and confirmation of design creation by using data Genebank www.ncbi.nlm.nih.gov with access numbers obtained EU077226 primary HPV-52 L1 two primers (Table 1). The results of amplification using forward and reverse primer obtained fragments of HPV-52 L1 throughout 1500 bp (Figure 1), while the HPV-16 L1 amplification used a primer pre-existing (Table 1). The results of amplification using forward and reverse primer obtained fragments of HPV-16 L1 throughout $1500 \mathrm{bp}$ (Figure 2). The results sequences processed using software ClustalX 2.1. and MEGA6.06. The results of phylogenetic analysis showed that the isolated DNA of HPV in Bandung has a kinship with those in EU077219 Canada (America) and KT799980, KU951191.1 Southwest China (Asia).

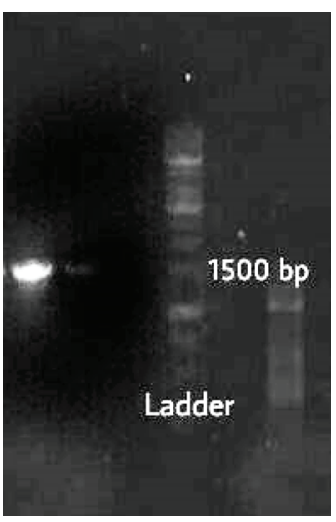

Figure 1. Electrophoresis HPV-52 L1 gene results for Polymerase Chain Reaction. The results of amplification using forward and reverse primer obtained fragments of HPV-52 L1 throughout $1500 \mathrm{bp}$.

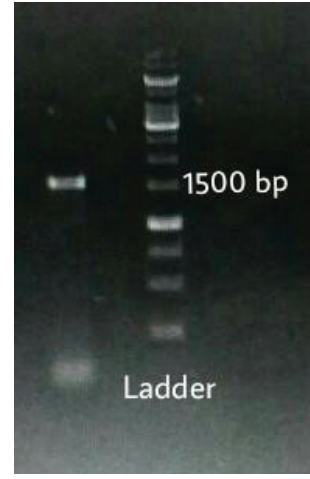

Figure 2. Electrophoresis HPV-16 L1 gene results for Polymerase Chain Reaction. The results of amplification using forward and reverse primer were obtained fragments of HPV-16 L1 throughout $1500 \mathrm{bp}$.

\section{Discussion}

The most often HPV genotypes which infect cervical cancer patients in Indonesia were HPV-16, followed by HPV-18, and HPV-52.(3) The distribution of HPV in various regions of the world is different. Based on the analysis of sequences of L1 HPV variants are distinguished in five phylogenetic clusters which are European (E), Asia (As), Asian American (AA), Africa 1 (AF1), and Africa 2 (AF2).(12) Variations on each HPV have a risk of carcinogenic effects, such as variation of HPV-16 has a high-risk carcinogenic effect in Asian-American and African variants rather than European variants. While the HPV-52 variations have risk of carcinogenic in Asia and European variants.(13)

In the phylogenetic tree, nitrogenous bases isolate HPV-52 Bandung has bootstrap 66\% (Figure 3). This is a method to evaluate the feasibility of phylogenetic trees. Bootstrap above $50 \%$ indicates acceptable phylogenetic tree. Isolate HPV-52 Bandung was located in the same cluster with Canada (America), Southwest China (Asia), HongKong (Asia), Japan (Asia), China (Asia) and the USA, but different clusters to isolate Canada EU077226. The access number is used as a reference sequence of the primary manufacture. Each cluster is divided into groups and subgroups. The first cluster, isolate Canada shows separated from isolate China. Isolate HPV-52 of cervical cancer patients in Bandung (Indonesia) were in a subgroup with the isolates originating from EU077219 Canada (America) and KT799980 Southwest China (Asia). Thus it can be concluded that the Bandung isolate has a closer kinship with isolates originating from Canada and Southwest China compared with isolates originating from HongKong, Japan, and the USA.

Based on the search results, the origin of HPV-16 L1 of the DNA isolate infecting patients the HPV-16 and HPV-52 were in the same cluster with isolate HQ644246.1 


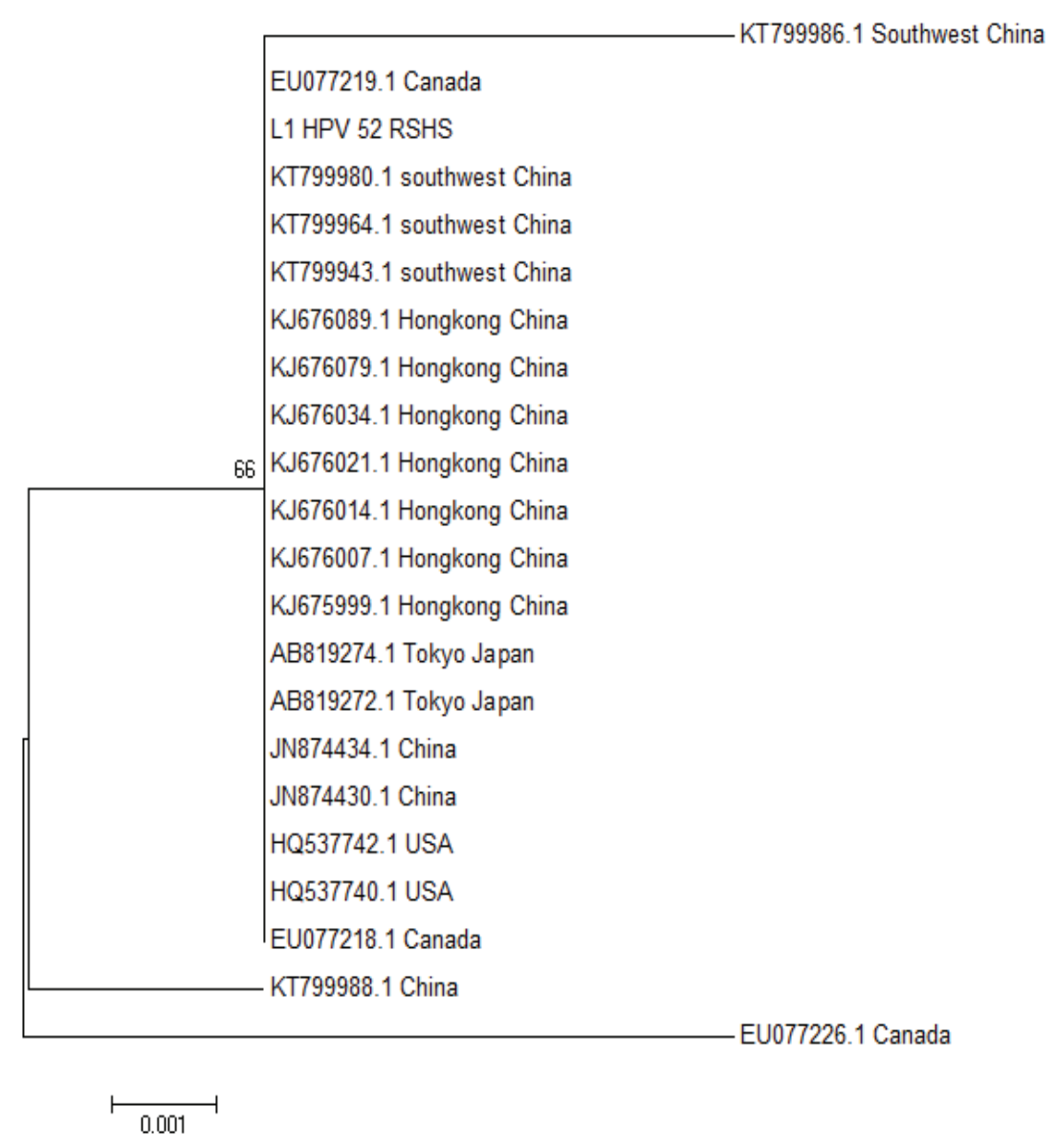

Figure 3. Phylogenetic tree of HPV 52 L1 Nitrogen Bases with Neighboor-Joining method Pylogenetic Tree MEGA 6.06. (11) Isolate HPV-52 Bandung was located in the same cluster with Canada (America), Southwest China (Asia), HongKong (Asia), Japan (Asia), China (Asia), and the USA, and different clusters to isolate Canada EU077226 access number are used as a reference sequence of the primary manufacture.
Figure 4. Phylogenetic tree of HPV 16 L1 Nitrogen Bases with Neighboor-Joining method Pylogenetic Tree MEGA 6.06. (11) The search results the origin of HPV$16 \mathrm{~L} 1$ of the DNA isolate infecting patients the HPV-16 and HPV-52 were on one cluster with islolat HQ644246.1 (USA), and EU430680.1 (China) as well as being in one subgroup isolates KU951191.1 (Southwest China). 
(USA), and EU430680.1 (China). It also and has bootstrap $70 \%$ (Figure 4) with isolates KU951191.1 as well as being in one subgroup isolates KU951191.1 (Southwest China). These results indicate that the majority of isolates of patients with cervical cancer in Bandung contained in one cluster to the origin isolate of other Asian countries. This is consistent with previous studies conducted in Bandung by Fadhilah with HPV-16 isolates that have origins kinship with isolates from Asia and East Asia (14) and the research conducted by Suhandono on isolate single HPV-52 infection that has real origin kinship with the isolates from the Philippines (Asia).(15)

This shows that there are certain types of HPV genomes that were clustered according to the ethnic people and regions where they are isolated. It has been shown by HPV-16 and represents the lineage of HPV variants are genetically inherited.(12) The types of HPV that mostly infect women in Asia are HPV -16 (2.5\%), HPV-18 (1.4\%), and HPV-52 (0.7\%).(16) The distribution of HPV types is based on the proximity of the geographical location, ethnically, and lifestyle of the individual.(17)

From the results of this study, the isolates in Bandung HPV L1 genes have origins kinship with isolates from EU077219 Canada and KT799980, KU951191.1 Southwest China. It is based on the characteristic of L1 isolate genes in Bandung which is similar to the ones in Canada (America) and Southwest China (Asia), compared to other isolates.

Limitation of this study is the result of sequence HPV52 and HPV-16 is not full length resulting in a slight variation of kinship between HPV-52 and HPV-16 in Indonesia and other countries.

\section{Conclusion}

HPV-L1 gene sequence of HPV-16 and HPV-52 isolates from multiple infections of HPV-16 and HPV-52 in cervical cancer patients in Bandung refers to the L1 gene variation in Canada and Southwest China. This proves that Indonesia's HPV clusters are found in the strains of America and Asia.

\section{Acknowledgments}

Thanks to Academic Leadership Grant (ALG) No. 872/ UN6.3./LT/2017 for financial support. Also thanks to Afandi
Charles, Vera Amalia Lestari and Moch. Syarif Hidayatullah from Faculty of Medicine Universitas Padjadjaran for fruitful discussion.

\section{References}

1. Ferlay J, Soerjomataram I, Dikshit R, Eser S, Mathers C, Rebelo M, et al. Cancer incidence and mortality worldwide: Sources, methods and major patterns in GLOBOCAN 2012. Int J Cancer. 2015; 136: E359-86.

2. Catarino R, Petignat P, Dongui G, Vassilakos P. Cervical cancer screening in developing countries at a crossroad: Emerging technologies and policy choices. World J Clin Oncol. 2015; 6: 28190 .

3. Vet JNI, de Boer MA, Van den Akker BEWM, Siregar B, Lisnawati, Budiningsih $\mathrm{S}$, et al. Prevalence of human papillomavirus in Indonesia: a population-based study in three regions. Br J Cancer. 2008; 99: 214-8.

4. Bruni L, Barrionuevo RL, Albero G, Aldea M, Serrano B, Valencia S, et al. Human papillomavirus and related diseases in Indonesia. ICO Information Center on HPV and Cancer. 2015; 23: 74.

5. Bzhalava D, Guan P, Franceschi S, Dillner J, Clifford G. A systematic review of the prevalence of mucosal and cutaneous human papillomavirus types. J Virol. 2013; 445: 224-31

6. Thomsen LT, Frederiksen K, Christian M, Junge J, Castle PE, Iftner $\mathrm{T}$, et al. High-risk and low-risk human papillomavirus and the absolute risk of cervical intraepithelial neoplasia or cancer. J Obst and Gynecol. 2014; 123: 57-64.

7. International Agency for Research and Cancer. IARC Monograph Biological Agents: Volume 100B A Review of Human Carcinogens. Lyon: International Agency for Research and Cancer; 2012

8. Bernard HU, Burk RD, Chen Z, Van Doorslaer K, Hausen H zur, de Villiers EM. Classification of papillomaviruses (PVs) based on 189 PV types and proposal of taxonomic amendments. J Virol. 2010; 401: 70-9.

9. Tobing MDL, Sahiratmadja E, Dinda M, Hernowo BS, Susanto H. Human papillomavirus genotypes profile in cervical cancer patient at Dr. Hasan Sadikin General Hospital, Bandung Indonesia. Asian Pac J Cancer Prev. 2014; 15: 5781-5.

10. Sahiratmadja E, Tobing MDL, Dewayani BM, Hernowo BS, Susanto $\mathrm{H}$. Multiple human papilloma virus infections predominant in squamous cell cervical carcinoma in Bandung. Univ Med. 2014; 33: 58-64.

11. Hall BG. Building phylogenetic trees from molecular data with MEGA. J Mol Biol Evol. 2013; 30: 1229-35.

12. Burk RD, Chen Z, Van Doorslaer K. Human papillomaviruses: Genetic basis of carcinogenicity. Public Health Genomics. 2009; 12: 281-90.

13. Chen Q, Luo Z, Lin M, Yang L, Yang L, Ju G. Evaluation of the genetic variability of human papillomavirus type 52. Int J Mol Med. 2012; 30: 535-44.

14. Fadhilah FR, Sahiratmadja E, Safitri R, Maskoen AM, Susanto H. Analisis filogenetik gen $\mathrm{L} 1$ human papillomavirus 16 pada penderita kanker serviks di Bandung. Majalah Kedokteran Bandung. 2015; 47: $174-8$ 
15. Suhandono S, Kencana UDA, Kristianti T, Sahiratmadja E, Susanto H. Cloning, expression and bioinformatic analysis of human papillomavirus type $52 \mathrm{~L} 1$ capsid gene from Indonesian patient. Microbiol Indones. 2014; 8: 94-102.

16. Kantathavorn N, Mahidol C, Sritana N, Sricharunrat T, Phoolcharoen $\mathrm{N}$, Auewarakul, et al. Genotypic distribution of human papillomavirus (HPV) and cervical cytology findings in 5906 Thai women undergoing cervical cancer screening programs. Inf Agents and Cancer. 2015; 10: 7. doi: 10.1186/s13027-015-0001-5

17. Baloch Z, Yasmeen N, Li Y, Ma K, Wu X, Yang S, et al. Prevalence and risk factors for human papillomavirus infection among Chinese ethnic women in southern of Yunnan, China. Braz J Infect Dis. 2017; 21: 325-32. 